\title{
Seismic behaviour of reinforced concrete frame with infill panels
}

\author{
Mrs. Sanaa Elmalyh ${ }^{1}$, Mr. Azzeddine Bouyahyaoui ${ }^{1}$ and Mr. Taoufik Cherradi ${ }^{1}$ \\ ${ }^{1}$ Mohammadia School of Engineers, University of Mohammed V, Dept. of Civil Engineering, Agdal, Rabat, Morocco
}

\begin{abstract}
Infill panels are usually used in structures; therefore, it is very important to study their behaviour and their influence on bare frames. Several models had been proposed to understand the effect of the infill panels on structure. The aim of this work is to identify the effect of the presence of infill panels on bare frames. The diagonal stiffness and shear compression failure of the structure, the nonlinear behaviour of the infilled frame under axial loading and the relation between the strength, ductility and stress-strain of different previous experiments will be presented. Experimental research on the interaction between the steel frames and infill panels has been done to determine the behaviour of steel frames with different types of infill walls. Many frames with composite panels subjected to cyclic-loading were realized to determine the damping ratio, the static and dynamic response, strength and stiffness degradation of infill elements. The objective of this paper is to represent and analyze the hysteretic behaviour, failure modes, and the variation of different parameters of the infilled bare frame like stiffness, strength, ductility and loading displacement curves.
\end{abstract}

\section{Introduction}

The non-linear behaviour of the infilled frame under seismic loading is very complex, thus it is very difficult to predict it just by analytical models. Therefore, experimental studies are necessary to predict this behaviour.

The presence of infill frame affect in a direct way, stiffness, strength and energy dissipation of the structure. In seismic zones, the interaction between the infill panels and bare frames influence the seismic response of the structure. The collapse of infilled reinforced concrete frames exposed to earthquake loading is caused in the most of the cases by the presence of infill panels and by the insufficiency of shear resisting capacity due to the lack of ductility and resistance of reinforced concrete bares. Finite element analysis can simulate the non-linear comportment of reinforced concrete elements of the model even if the non-linear response of each material has a complicated behaviour. The presence of the infill panels has an important effect on the behaviour of the bare frame, because the infill panels alter the mechanical characteristics of the portico under seismic loading, and their presence can influence the strength, stress, stiffness and ductility of the structure.

The paper presents a review of different experiments that had been done by many researchers to analyze the effect of the presence of infill panels on the behaviour of the Infilled RC frame under seismic cyclic loading.

\section{Objective and scope}

The goal of this research is to evaluate the risks of infill panels on the behaviour of bare fames. Also among the objectives of this work is to:

- Identify the mechanism failure of masonry walls, the stiffness, ductility and energy dissipation.

- Classify the behaviour mechanism of infill panels.

- Compare experimentally the response of model with fully and partially infill walls.

- Examine the influence of infill panels on the seismic response of the structure.

For that purpose, analytical and quasi-static cyclic experiments had been done by many researchers to evaluate the influence of infilled walls on bare frames, through different physical parameters of the model like the height, mortar formulation and the constituent of the wall, to study the influence of a cyclic loading on in-plane and out-ofplane drift. In this part, the description of the previous experiments program, materials, the connections between different elements, the method of function of the system used for test, the measure of the model, the test setup and loading are summarized. Moreover, the results of the experimental test such as, displacement, strength, stiffness, hysteresis response, failure mechanism, drift ratio, and the different types of damage in terms of different type of models will be defined.

\section{Literature review}

Infilled frame had been studied by many researchers to understand the behaviour of widespread strength of the Infilled RC-frame. [1] Had tested three-dimensional surfaces to determine the failure surface of masonry subjected 
to biaxial stress using a cubic tensor polynomial. Besides, [2] had reviewed the most criteria present in the literature and codes to interpret, the possible failure modes for masonry piers under in plane loading. Furthermore, [3] had evaluated the possibility of achieving a high level of ductility by flexural yielding in fully grouted reinforced concrete masonry shear walls; for that, six full-scale walls were tested to failure under reversed cyclic lateral loading to investigate the effect of the amount and distribution of vertical reinforcement and the level of axial compressive stress of the inelastic behaviour and ductility. Results showed that yielding of the outermost vertical bars extended to a height equivalent to half the wall length. In addition, the top wall displacement at the onset of yielding of the vertical reinforcement was highly dependent on the amount of reinforcement, but only minimally affected by the level of axial compressive load. However, at maximum loads, the displacements were less sensitive to either the amount of vertical reinforcement or the level of axial compression. Correspondingly, the displacement ductility was found to be very sensitive to the amount of vertical reinforcement, but was not dependent on the level of axial compression. In general, high levels of ductility and energy dissipation capabilities accompanied by relatively small strength degradation were observed for the test specimens.

The irregularity related with undefined location of infill walls could make undesirable effects on the general behaviour of structures [4].

[5] Had proposed a macro-model to simulate the comportment of infill panels, which were presented by two equivalent struts to study the global and local responses. Finite element analyses had been done to compare the results to experimental data, in order to evaluate the local effects on the frame and underline the influence of the coefficient of friction at the infill-frame interface. It was concluded that the presence of infill increases the stiffness and modifies the dynamic response of the structure.

The internal forces produced by the interaction of the infilled frame, were not supported by the bare-frame, caused by an additional shear force arising at the ends of beams and columns. This additional force can cause brittle collapse mechanisms. A parametric study was carried out addressed to the prediction of the shear forces. The results can be used as a support when the simplified model is adopted, consisting in substitution of infill with an equivalent in jointed concentric strut. Equivalent strut models do not present exactly the physics of the original systems; furthermore, information about the local shear transfer in contact regions can be ignored [6].

According to [7], the distribution of the original construction cost of the nonstructural elements of three types of buildings (offices, hospitals, and hotels) it is about $48 \%$ to $70 \%$ of the total cost. Therefore, the economic loss caused by nonstructural components is more of that due to structural components.

\subsection{Seismic provisions related to mortar type}

Mortars had been used to fill cracks and provide uniform bedding for masonry units. Such mortars were typically composed of clay, bitumen, or clay-straw mixtures. [8] Had studied the influence of grouting on the compressive strength of masonry prisms, results showed that grouted masonry prisms have failure loads, lower than those predicted using superposition to combine the capacity of the grouted area and the capacity of the unit area. Results indicate that the compression strength of grouted masonry can be expected to be less influenced by mortar properties than that of ungrouted masonry due to the dominance of the grout with respect to the failure mechanism. It was also noted that fully grouted specimens typically display more uniform behaviour with less scatter than ungrouted specimens.

Currently, the Masonry Standards Joint Committee Code [9] prohibits the use of masonry cement (MC) mortars in the construction of lateral force resisting systems for structures that fall into Seismic Design Categories. Two factors have likely contributed to establishing and maintaining this ban: (1) MC mortars were not common in high seismic regions where seismic codes were developed and (2) research into the behaviour of the ungrouted (solid or hollow) masonry assemblages has shown that MC mortars typically display lower bond strength than PCL mortars. Clearly, the first factor is social in nature rather than related to the actual seismic performance of shear walls constructed with masonry cements. The second factor, while well established, may not have as large an influence on seismic performance as expected.

\subsection{Models subjected to in-plane actions}

The in-plane behaviour of shear walls is so complex to lateral force resisting of the structure, as consequence their failure cause ruin of the structure. Many researchers have studied the reaction of infilled panels to quasi-static reversed-cyclic displacement. This part presents a summary of existing researchers and their results founded in the literature.

[10] Have reported the structural behaviour of a frame, with masonry wall subjected to in-plane monotonic loading by full-scale test and the method of discontinuous deformation analysis.

[11] Had studied reinforced concrete (RC) frame with the middle bay brick infilled, representing a five stories, three bay building in quarter-scale. As a result, the frame developed beam and column hinging near beam column interface before they reached their maximum story shear force and they eventually failed due to joint shear, exhibiting successive strength drops. The frame exhibited diagonal crack failure at brick infill in the bottom story at a relatively slow rate of increase before they started to break down. After the collapse of brick infill in the bottom story, it was acting as a soft story. The contribution of the infill brick was significant up to breaking. The strain measured in infilled beams and columns are $20 \%$ lesser than bare frame beams up to failure brick infill. For, [12] results show that the response of the total walls is not sensitive to 
the reinforcement pattern, but it is sensitive to the aspect ratio of the wall.

It is clear that only if the infill is separated from the frame and a sufficient gap exists, then it can be considered that the frame and the panel do not interact. This solution is rarely used in common practice due to the difficulties related to connecting the walls to the frame. Out-of plane loads need to be withstood, while allowing free in-plane deformations and ensuring a good thermal and sound insulation. Moreover, if there is a gap only at the top of the wall, between the infill and the frame, a negative effect could occur: the compression strut acts more on the columns, which leads to a faster increase of shear forces [13].

\subsection{Models subjected to out-of-plane actions}

Several research had been done to evaluate the out-ofplane behaviour of partially and fully infill panels, such as [14], this research was based on the experimental testing approach where the walls were loaded out-of-plane using inflatable air bags. Testing was performed on ten unreinforced masonry walls, with cavity walls in two separated buildings. The test walls were isolated into vertically spanning panels. The walls are in reinforced concrete block and walls having a rigid top edge restraint consisting of a RC slab or beam were assumed to be subjected to the arching action during loading. The retrofit cavity ties used in this study included both mechanical and adhesive ties and was installed in each test specimen along two vertical lines separated by approximately $600 \mathrm{~mm}$ horizontally. Cavities between brick wythes were typically $50 \mathrm{~mm}$. All the test walls were loaded semi-cyclically at a quasi-static loading rate. The maximum in-test $\mathrm{g}$-force value for each wall was determined by dividing the maximum total test load by the weight of the test wall. Where the walls could be tested to complete collapse, the instability drift was measured using photogrammetry. It was concluded that, the top rigid restraint from the building frame causing "arching action" could greatly increase the OOP capacity of vertically spanning infill walls. For relatively low slenderness ratios (i.e., ratios of wall height to effective thickness), the ratio of strength-based capacity between a cavity wall with arching action and a similarly retrofitted cavity wall without arching action (e.g., Has-W1 and Has-W3, respectively) was observed to be as high as 4 , "figure 1".

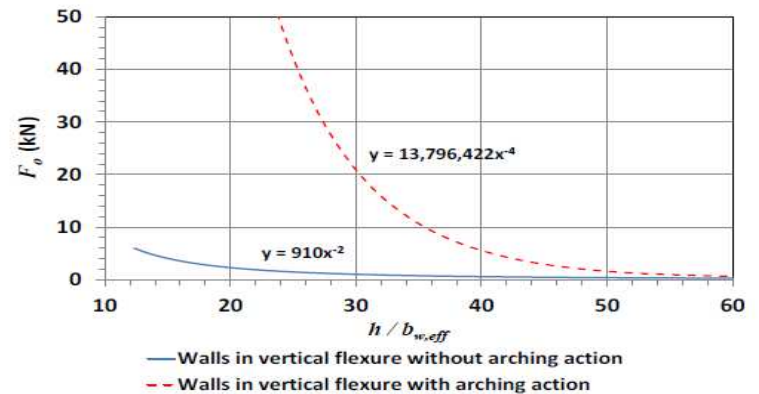

Fig. 1. Sensitivity of two considered OOP wall capacity models to changes in slenderness ratio

Furthermore, cavity tie retrofits with adequate spacing, as well as adequate compressive and shear stiffness, can greatly improve the OOP capacity of URM cavity walls, especially for walls with arching action. For a force-based analysis in one case-study, the cavity wall OOP strength was more than doubled when comparing the existing condition (i.e., Has-W5) to the condition in which new ties were vertically spaced at approximately $150 \mathrm{~mm}$ (i.e., Has-W6). The adhesive cavity ties considered in this study were not notably more useful to improving OOP cavity wall performance than were more easily installed mechanical cavity ties. In addition, [15] had evaluated the outplane response of masonry infill panels when damaged due to in-plane forces. Two half-scaled specimens of large slenderness ratio $(\mathrm{h} / \mathrm{t}=23)$ were subjected to simulated seismic load through a shake table. The out-of-plane objective was chosen as N21E component of the 1952 Taft earthquake with PGA of $0.156 \mathrm{~g}$ and total duration of $54.16 \mathrm{~s}$ "figure $2 \mathrm{a}$ ". The first $30 \mathrm{~s}$ of ground motion was considered for the simulation, which includes the strong motion portion, and the time axis of the accelerogram was scaled by a factor $1 / 2$ to satisfy the similitude relations.

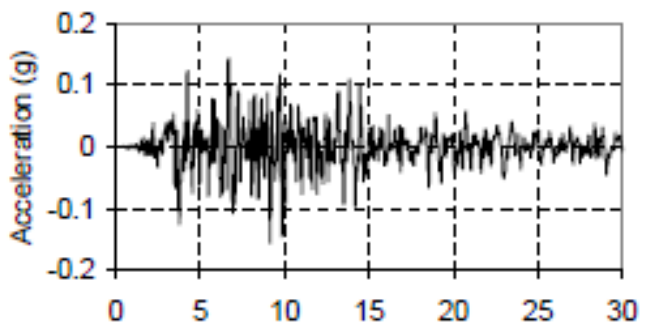

(a) Time (s)

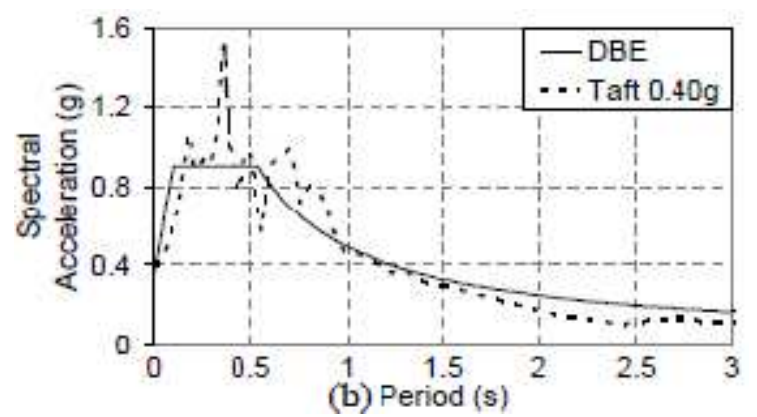

Fig. 2. (a) TAFT N21E ground motion (b) Comparison of response spectra of DBE and TAFT motion

As results, the big parts of the cracks were produced by the in-plane loading, the cracks form at initial stages of the in-plane loading developed and energy dissipation caused principally by sliding along the bed-joints. The first specimens indicate a diagonal bed joint cracking pattern, while the second specimen showed a sliding along the parallel bed joints and uniformly distributed cracks "figure 3" \& "figure 4". The two models attain their maximum in-plane strengths of $32.2 \mathrm{KN}$ and $39.1 \mathrm{KN}$ at $7.50 \mathrm{~mm}$ and $11.25 \mathrm{~mm}$ displacement. 


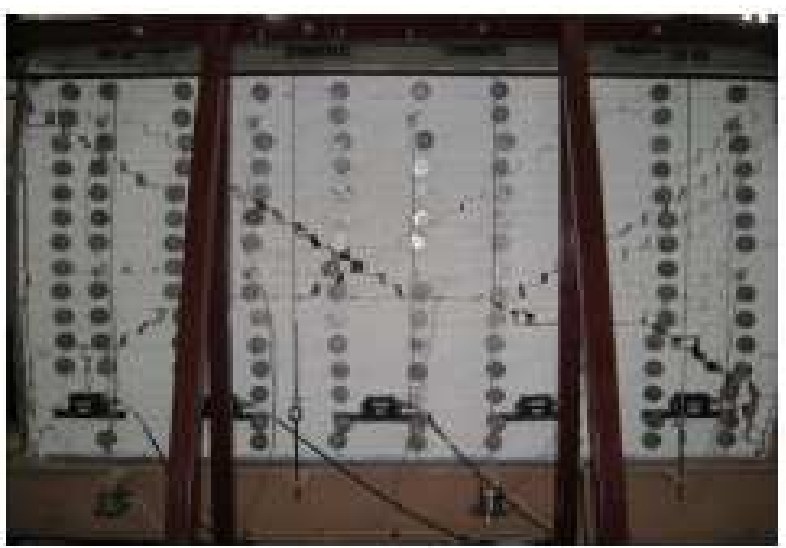

Fig. 3. Cracking pattern in the first specimen after $1.0 \%$ inplane drift cycles and arching phenomenon before failure under out-of-plane shake table motion

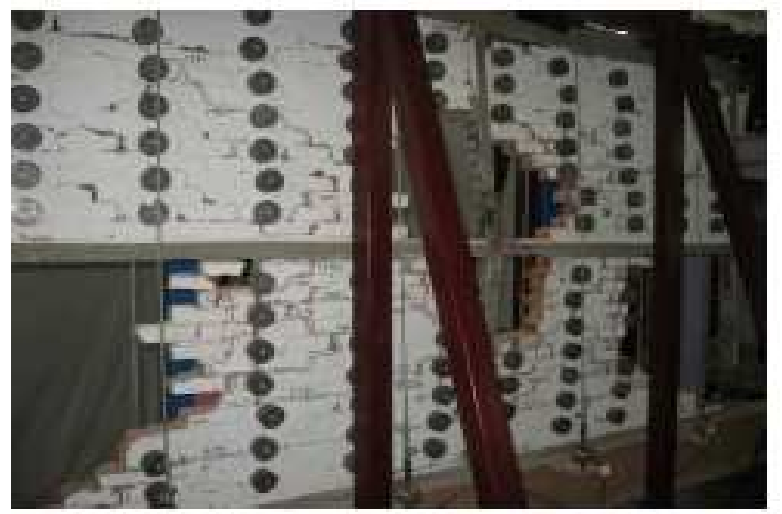

Fig. 4. Cracking pattern in the second specimen after $1.0 \%$ inplane drift cycles and partial collapse of masonry due to out-ofplane motion after $2.2 \%$ in-plane drift cycles

For the out-of-plane loading, very few cracks were created. The first model collapsed during out-of-plane loading after $1.2 \%$ in-plane drift cycles, showed large out-of plane deflection, and arching before the failure. For the second model with interior grid elements, a partial collapse of masonry sub-panels were observed after $2.20 \%$ in-plane drift cycles, along with the failure of the interior vertical grid element at mid height.

As results, the two experimental models reached attained their maximum peak accelerations in the undamaged state, but after the damage was introduced, and a small deflection was observed in the second model, which could be caused by the confining effect that the interior grid generated which help in reducing out-of-plane deflections. The acceleration response decreased and was observed to saturate to a lower value with continued in-plane damage "figure 5".
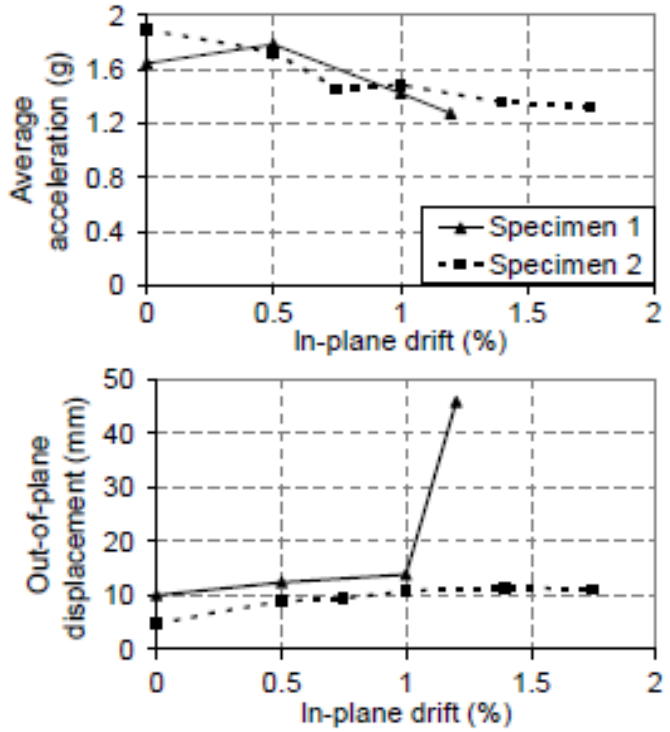

Fig. 5. Variation of average acceleration and out-of-plane displacement with in plane drift (Damage)

In addition, the variation of the acceleration en function of the height of the models shown in "figure 6", the interior grid elements provided in the second model seems not very important to modify the acceleration response. Therefore, the maximum acceleration response for two specimens was nearly similar.
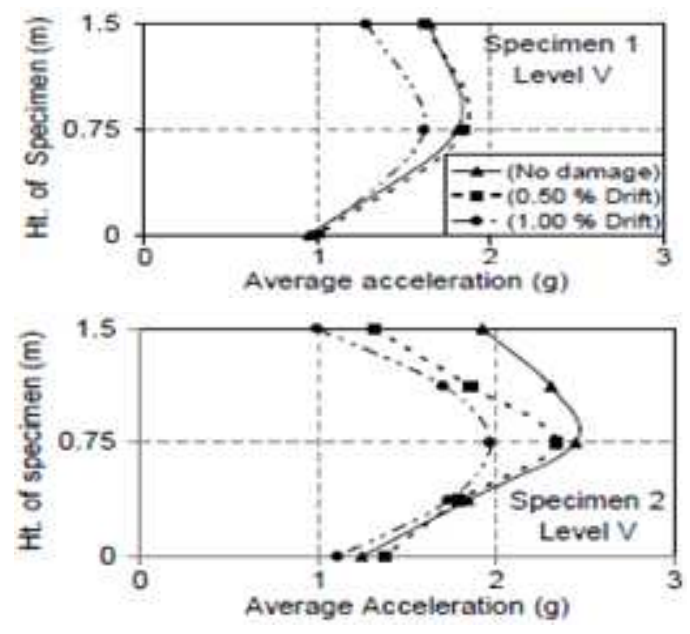

Fig. 6. Variation of average accelerations along the height of specimen

The sliding movement of sub-panels with the grid elements allowed better energy dissipation and grater deformability, without much reduction in lateral resistance. In addition, the in-plane load-displacement response presented enhanced the capacity of infill panel with interior grid elements "figure 7". 

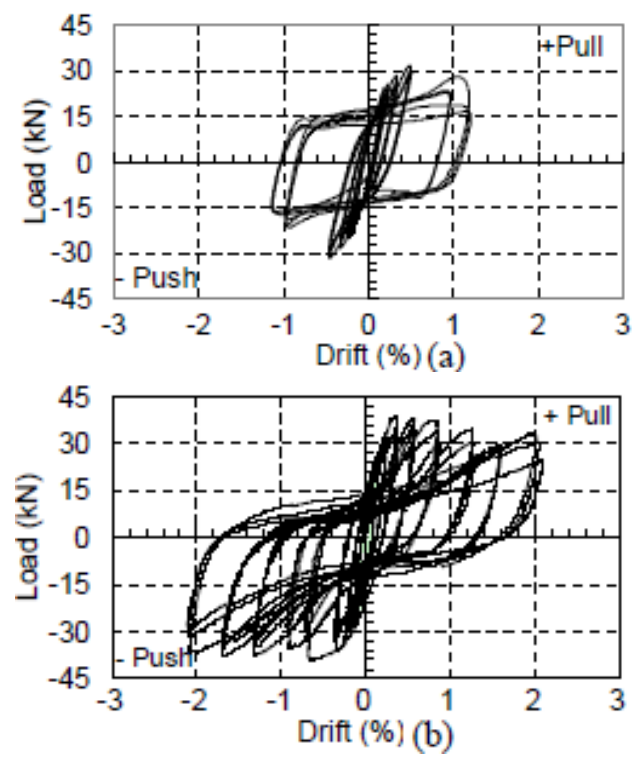

Fig. 7. Load-displacement curve (a) Specimen 1 (b) Specimen 2

Many National and International Standards have recommended different empirical formulations to tackle the above problem by dividing it into two parts; (i) Bare framed structure and (ii) Framed structures with masonry infill. They do not give due consideration to the location and the percentage of infill in the structures [16].

Extensive researches have been carried out worldwide in the last five decades. Many methods have been developed for the dynamic analysis of RC frames with masonry infill incorporating one or more simplifying assumptions regarding its stiffness. Unreinforced Masonry (URM) infill panels have a very high initial in-plane lateral stiffness and low deformability. Therefore, under seismic loads, the existence of URM walls change the whole lateral force transfer mechanism of the structure from a predominant frame action to predominant truss action [17].

The behaviour of 3D RC frames with various configurations \& amount of masonry infill, under dynamic loading conditions has been studied by [18], components of the structure i.e., structural sub-assemblages of columns, beams and slabs were casted from the same materials. A series of various ground motion tests were performed in the building models using servo controlled hydraulic actuator. As a conclusion the masonry infill although do not interfere in the vertical load resisting system for the RC frame structures, they significantly affect the lateral loadresisting system. Also, the effect of de-bonding of masonry infill with RC frames as the base acceleration is increased, moreover, the natural frequencies and damping reduces. For the natural frequencies and damping values had been high in the presence of masonry infill. In addition, the decrease in the natural frequency is more, when the masonry infill is not constructed in the lower floor as compared to the upper floors without masonry infill. This is due to the contribution of walls towards the stiffness being more in the lower floors as compared to the upper floors. Moreover, there is an increase in the natural frequency when the masonry infill is not constructed in the upper floors. From this, it can be concluded that the contribution of masonry infill towards the mass is more in the upper floors as compared to the lower floors.

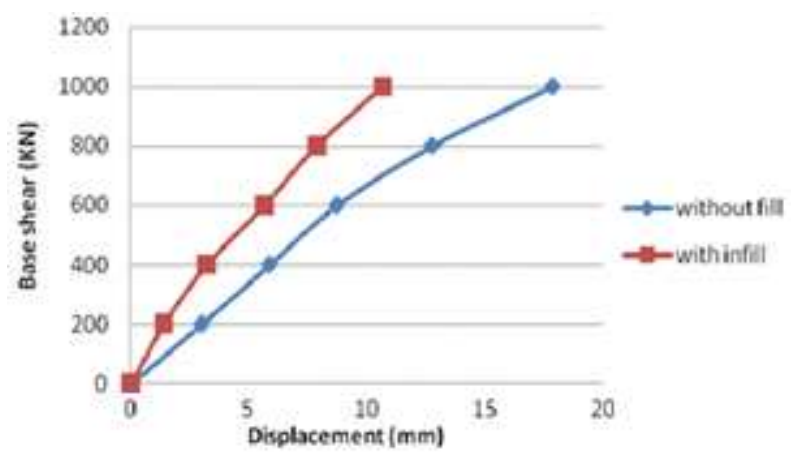

Fig. 8. Pushover Curve

[19] Had tested three full-scale wall specimens with different schemes, to improve the seismic comportment of shear-type damage of lightly RC walls. Two specimens were improved using supplementary RC panel and ultrahigh strength fiber reinforced concrete panel to avoid shear failure. The other specimen had been improved reinforcement details to enhance shear capacity and flexural ductility. The test results had been compared with past lightly RC wall test as a reference wall, which failed prematurely in shear reproducing the failure observed in the field. The variations of the eventual failure mode and the damage process were detected. The experimental specimens indicated ductile and stable behaviour with less damage compared with the reference wall. Also, this test, prove that RC and UFC panels enhanced the behaviour of lightly $\mathrm{RC}$ wall and stopped crack creation in the central part of the wall panel. Also, increasing the amount of horizontal reinforcement and providing confinement in the boundary regions controlled the opening of crack width and made the structure more ductile.

\section{Conclusion}

Stiffness, strength, energy dissipation and mechanical behaviour of bare frames are more significant enhanced when the infill panels were taken into consideration in buildings. The contribution of infilled panels, steel not taken into account in the design, because of the insufficient information about the interaction between infill panels and RC frames. However, their interaction needs more investigation. From those experimental researches, we can conclude that:

- The presence of Infill panels in the structure modify in a direct way the stiffness, the strength, deformation, failure mechanisms and energy dissipation of RC frame under lateral loads .

- The damage caused like shear sliding in the joints, the crush of infill, diagonal tensile cracking, and plastic hinges, depends on the physical characteristics of the different element, the ratio between the infilled and the $\mathrm{RC}$ frame and the infilled RC frame interface.

- A number of models have been used to predict the component of infilled frames. However, there is a less of experimental studies, which work on RC frame with the presence of infilled. In addition, the existing codes 
considered that infilled do not have an important influence on the RC frame. For that additional studies and experimental investigation must be done.

- The negligence of the presence of infilled walls can highly influence the mechanical characteristic of RC frame that can lead to unacceptable economical damage.

- The remarkable strength and stiffness of frames with and without infills prove the importance role of infill panels in the structure, consequently the infill panels must be taken into consideration in the design of the structures.

- The presence of infill panels in frame building makes significant modifications in the mechanical characteristics of the structure.

- The presence of infilled reduces the displacement capacity of the structure.

- The response of infilled frames had been simulated by the application of loads in compression in structure with equivalent diagonal struts, which might not consider the evolution forces in frame members.

- Brittle failure produced by shear forces was undervalued.

-When the interaction between infill panels and bare frame is taking into consideration the mechanical characteristic of the structure changes.

- The infill panels has an important role in resisting to lateral forces like earthquake and wind.

- The interaction between in-plane and out-of-plane panels was not taken into consideration.

Different models evaluated the contribution of infillpanels on the behaviour of bare frames. The present work presented a review of many experimental studies. The future work will be focused on a finite element study on Infilled RC frame with different storey subjected to cyclic loading.

\section{References}

1. C. A. Syrmakezis, P.G. Asteris, "Masonry failure criterion under biaxial stress state”, Journal of materials in Civil Engineeting, ASCE, 13, No 1, Pages 58-64, (2001)

2. C. Calderini, S. Cattari, S.Lagomarsino, "In-plane strength of unreinforced masonry piers", Earthquake Eng. Struct. Dyn., 38, Issue 2, Pages 243-267, (2009)

3. M. T. Shedid; R. G. Drysdale; and W. W. ElDakhakhni, “,Behavior of Fully Grouted Reinforced Concrete Masonry Shear Walls Failing in Flexure: Experimental Results", M.ASCE, Journal of Structural Engineering, 134, Issue 11, November, (2008)

4. B. Kaushik, DC. Rai, SK. Jain, "Code approaches to seismic design of masonry-infilled reinforced concrete frames: a state-ofthe-art review”. Earthq Spectra, 22, 4, Pages 961-983, (2006)

5. F. Alessandra, A. Netti, P. Monaco, "The influence of masonry infill on the seismic behaviour of RC frame buildings", Engineering Structures, 44, Pages 133-145, Novembre (2012)
6. L. Cavaleri, F. D. Trapani, "Prediction of the additional shear action on frame members due to infills”, Bulletin of Earthquake Engineering, 13, Issue 5, Pages 1425-1454, May, (2015)

7. S. Taghavi, E. Miranda, "Response assessment of nonstructural building elements", PEER Report 2003/05, The Pacific Earthquake Engineering Research Center, Berkeley, CA, (2003)

8. R. G. Drysdale, A. A. Hamid, L. R. Baker, "Masonry structures: Masonry Structures Behaviour and Design”, 2nd Edition. The Masonry Society. Boulder, CO. (1999)

9. “Masonry Standards Joint Committee. Building Code Requirements for Masonry Structures”, ACI 530/ASCE 5/TMS 402. American Concrete Institute. American Society of Civil Engineers. The Masonry Society. Detroit, New York, Boulder, (2005)

10. Y.J. Chiou, J. Cherng and Y.W. Liou,, "Experimental and analytical study of masonry infilled frames", $J$. Struct. Eng., 125, Pages 1109-1117, (2006)

11. S. Arulselvan, K. Subramanian, E.B. P. Pillai and A.R Santhakumar, "RC infilled Frame-RC Plane Frame Interactions for Seismic Resistance”, Journal of Applied Sciences 7(7), Pages 942-950, (2007)

12. M. Maleki1 , R. G. Drysdale, A. A. Hamid, and A. A. El-Damatty, “ Behaviour Of Partially Grouted Reinforced Masonry Shear Walls-Experimental Study", 11th Canadian Masonry Symposium, Toronto, Ontario, May 31- June 3, (2009)

13. TUCEB Code for seismic design - Part I - Design rules for buildings. P100-1, (2013)

14. K. Walsh, D. Dizhur, J. Shafaei, H. Derakhshan, and J. Ingham, “ Out-of-Plane In-Situ Testing of Masonry Cavity Walls in As-Built and Improved Conditions", Australian Earthquake Engineering Society Conference, Nov 21-23, Lorne, Victoria, (2014)

15. D. C. Rai, S. Komaraneni and V. Singhal, "Out-OfPlane Seismic Behaviour Of Brick Masonry Infilled Panels With Prior In-Plane Damage”, 11th ,Canadian Masonry Symposium, Toronto, Ontario, May 31- June 3, (2009)

16. H. R. Tamboli, and U. N. Karadi , "Seismic Analysis of RC frame Structure with and without Masonry Infill Walls", Indian Journal of Natural Sciences, Vol. 3, Issue 14, Pages 1137-1194, (2012)

17. CVR. Murty, SK. Jain, " Beneficial influence of masonry infill walls on seismic performance of $R C$ frame buildings", In: 12th World Conference on Earthquake Engineering, Auckland, (2000)

18. R. Srinivasan, S. Suresh Babu, and Sidramappa V. Itti, "A Study on Performance of 3D RC Frames with Masonry in-fill under Dynamic Loading Conditions", KSCE Journal of Civil Engineering (0000) 00(0):1-7

19. E. Yuniarsyah, S. Kono, M. Tani, R. Taleb, H. Watanabe, T. Obara, T. Mukai, " Experimental study of lightly reinforced concrete walls upgraded with various schemes under seismic loading", Engineering Structures 138,Pages 1-15, (2017) 